\title{
A scenario-based multiple attribute decision-making approach for site selection of a wastewater treatment plant: Bahir Dar City (Ethiopia) case study
}

\author{
Tilik Tena Wondim ${ }^{1,2}$ and Bloodless Dzwairo ${ }^{1 *}$ \\ 'Durban University of Technology, Civil Engineering Midlands, PO Box 101112, Scottsville, 3209, South Africa \\ ${ }^{2}$ Bahir Dar Institute of Technology, Bahir Dar University (BiT-BDU), PO Box 26, Bahir Dar, Ethiopia
}

\begin{abstract}
The challenge of selecting an appropriate wastewater treatment plant (WWTP) site is addressed in this study, using the case study of Bahir Dar City, Ethiopia. An innovative approach is proposed for selecting the WWTP site. Fifteen practically feasible alternatives were identified based on the geographical information system (GIS) based hydraulic design and considering the overall economy of the system. The three dimensions of sustainability were considered while evaluating alternatives through incorporating economic, social, energy and environmental criteria in decision-making. The multiple attribute decision making (MADM) method was applied to prioritize the alternatives. Four scenarios representing the different perspectives of choices were used for weight elicitation. The results of the study show that the developed decisionmaking approach identified practically feasible alternatives. The framework and decision-making methodology developed in this study helped to facilitate the decision making by local government in a holistic view that incorporates environmental management in the city of Bahir Dar.
\end{abstract}

Keywords: urban planning, multiple attribute decision making, sewage outfall, sewerage system, site selection, wastewater treatment plant

\section{INTRODUCTION}

Globally, it is well-documented that increasing population size, rapid rates of urbanization, industrialization, and consequent increasing demands on water supply result in generation of polluted effluent and solid waste. At the same time, countries are still battling to increase water and sanitation coverage in order to meet demand (WHO/UNICEF, 2017).

For example, in Ethiopia, a study by Teshome (2007) revealed that water supply and sanitation coverage is one of the lowest in the world. Additionally, the 2015 report by WHO/UNICEF (2015) indicated that there had been moderate progress on sanitation coverage between 1990 and 2015, with the proportion of the 2015 population that gained access since 1990 sitting at $27 \%$. The particularly low sanitation coverage for Ethiopia has also been reported in earlier studies (Lüthi et al., 2010; Moe and Rheingans, 2006; WHO/UNICEF, 2006). Since sanitation and disease burden are correlated, , in Amhara region (where Bahir Dar City is located, in the northwestern part of Ethiopia) with a population of about 19 million, approximately 90000 children under 5 years of age die annually from diseases related to poor sanitation.

In Bahir Dar City, sanitation technologies like septic tanks, pit latrines, and ventilated improved pit latrines (VIP) have been declared to not be environmentally friendly. Moreover, Bahir Dar City has no centralized or decentralized wastewater collection, conveyance nor treatment technology. Hence, establishments discharge untreated wastewater directly into the nearby water bodies, with partial or no treatment. The challenge is then that improperly dumped faecal material

\footnotetext{
To whom all correspondence should be addressed.

e-mail: ig445578@gmail.com

Received 11 August 2017, accepted in revised form September 2018.
}

severely impacts the quality of ground and surface water resources (Kumie and Ali, 2005; O'Loughlin et al., 2006; Tilahun and Collick, 2011). In this context, it is essential for urban local bodies (ULBs) in Ethiopia to develop adequate sewerage and sanitation infrastructure facilities. The first step towards this would be to plan and design such facilities.

Thus, the present study focused on selection of a site for a wastewater treatment plant (WWTP) for Bahir Dar City. In this city, the available quantity of water is sufficient to meet the demand of the entire population; however, the available water resources have not been utilized efficiently. Besides, there is a long list of water-related problems, including lack of sanitation as well as pollution of surface and ground water (HEHECE, 2000). Hence, the challenges abound to increase food supplies and preserve environmental amenities because of inadequate freshwater conveyance systems and lack of wastewater treatment and reclamation systems. For Bahir Dar City, it is essential to devise an optimized sanitation system to mitigate against pollution of freshwater and enhance production of adequately recycled wastewater, which will considerably reduce ecological pressure on Lake Tana and the Blue Nile River. For these reasons, it becomes vital to choose the most suitable wastewater treatment plant sites, considering specific criteria and indicators.

Site selection has been a widely evaluated problem for many other facilities such as landfill site selection in solid waste management (Banar et al., 2007; Javaheri et al., 2006; Paul, 2012; Sumathi et al., 2008), nuclear power plant site selection (Kurt, 2014), and site selection of aquifer recharge with reclaimed water (Pedrero et al., 2011). Specifically, for on-site selection for WWTPs, there are limited studies reported in the literature. For those that are available, some have proposed a heuristic screening method for regional planning of wastewater treatment systems where the optimal location is selected based on transportation cost 
and regionalization efficiency. For example, Makropoulos et al. (2007) reported the use of a spatial decision support tool (DST) for optimal siting of wastewater treatment technologies. The tool was based on fuzzy logic and multi-criteria decision making (MCDM), which incorporated uncertainty and decision makers' attitudes towards risk in the decision making problem. Makropoulos et al. (2007) developed a DST based on MCDM for siting new WWTPs. A set of general, land-use planning, geomorphological, and hydrogeological criteria, and also a few specialized criteria, was used for the evaluation.

A novel approach is proposed in this work, integrating hydraulic model outcomes with indicators accounting for technical, economic and environmental criteria. The present approach differs from those of past studies in two major perspectives. Firstly, the sites considered for the evaluation were identified from an optimal geographical information system (GIS) based hydraulic design of a sewerage system in Bahir Dar City. Secondly, all possible practical criteria were considered for the evaluation.

\section{MATERIALS AND METHODS}

The overall method flowchart is presented in Fig. 1. Many factors such as field feasibility, energy consumption, cost and social issues were considered while developing methods for WWTP site selection. As shown in Fig. 1, the methodology is based on multiple tools and techniques of advanced planning and management. The following manuscript sections describe the method step-by-step.

\section{Geographical data and demographic analysis}

Bahir Dar City is located approx. $578 \mathrm{~km}$ north-northwest of Addis Ababa in the north-western region of Ethiopia, on the southern coast of Lake Tana. The geographical location of Bahir Dar City lies between longitude $37^{\circ} 20^{\prime} 0^{\prime \prime} \mathrm{E}$ and $37^{\circ} 28^{\prime} 0^{\prime \prime}$ $\mathrm{E}$ and latitude $11^{\circ} 30^{\prime} 40^{\prime \prime} \mathrm{N}$ and $11^{\circ} 36^{\prime} 35^{\prime \prime} \mathrm{N}$. The city is at the emerging point of the Blue Nile River and is surrounded by ancient monasteries, which are tourist attractions. The study area consists of 4 zones. According to the 2006-2007 population and housing census results, the population of the city was 180770 (CSA, 2006-7). The predicted growth rates and zone wise populations are given in Tables A1 and A2 in the Appendix, respectively. The city has an approximate area of 42000 ha of which 2258 ha (17.2\%) are covered with water bodies. Of the total land area, 3842 ha are suitable for construction while the rest is unused land (BDIDP, 2006). The land use map, road network map, river map, digital elevation model (DEM) map, and soil map were used for this study.

Wastewater management practices in Bahir Dar City are not adequate and there is need for large infrastructure development. Most of the existing individual housing does not have access to a sewer network but rather uses pit latrines and septic tanks. Moreover, wastewater-generating institutions do not have their own wastewater treatment and management systems. Their wastewater disposal provisions are not different from those of individual housing units in the city. They also discharge wastewater into Lake Tana and the Nile River through pipes and open ditches. Such discharges pollute the environment, create offensive smells and aggravate the conditions for spreading communicable diseases (Mekonnen, 2012; Suominen et al., 2010).

\begin{tabular}{|l|c|c|}
\hline \multicolumn{3}{|c|}{ TABLE 1 } \\
Projected design flow rate from each service \\
\hline $\begin{array}{l}\text { Sources of sanitary } \\
\text { wastewater }\end{array}$ & $\begin{array}{c}\text { Design sanitary load/ } \\
\text { flow (MLD) }\end{array}$ & $\begin{array}{c}\text { Bahir Dar City } \\
\text { per capita water } \\
\text { supply demand } \\
\text { (LPCD) }\end{array}$ \\
\hline Residential area & 53.18 & 135 \\
\hline Commercial area & 2.37 & 15 \\
\hline $\begin{array}{l}\text { Small manufacturing } \\
\text { plant* }\end{array}$ & 3.98 & 25 \\
\hline $\begin{array}{l}\text { Total Sanitary load/ } \\
\text { Flow }\end{array}$ & 59.53 & \\
\hline${ }^{*}$. & & \\
\hline
\end{tabular}

${ }^{*}$ Small manufacturing plants are very limited in the city and this study only considered the beverage and food processing factories (semi industrial wastes that will be treated along with municipal waste).

\section{Hydraulic design (identification of possible sites)}

Bahir Dar City sewerage system design was carried out in order to identify possible sites for a WWTP (outfalls). The wastewater generation was estimated for residential, commercial and small-scale industrial or manufacturing plants based on population projections. The average dryweather flow was calculated based on per capita water supply demand of Bahir Dar City. It was assumed that $80 \%$ of water supply was generated as sanitary wastewater and the peak dry-weather flow was obtained by multiplying the average dry-weather flow by the peaking factor of 2.25 for the design population. The estimated load from each service is shown in Table 1.

The hydraulic design was carried out using ArcGIS and SewerGEMS software. Projected population (Table A2, Appendix), land-use map, elevation map, road network map and current condition of the city were taken into consideration for the sewerage system design and analysis. For the purposes of this study, the locations of sewage outfalls shown in Fig. 2 were decided based on a flow accumulation map (final pouring points, i.e., lowest elevation). Based on these locations (outfalls) the sewerage network was designed and simulated in SewerGEMS. Thus, Fig. 2 shows the outcome of the hydraulic model.

\section{Articulation of possible alternatives}

As shown in Fig. 2, 5 possible locations for WWTPs were identified. After screening the results from hydraulic design, it was found that it was not possible to transfer the wastewater from the location of Outfall 5 due to the $U$ shape of the lake in between OF- 5 and other outfalls (simply, OF-5 is located north-west of the lake while other outfalls extend from northeast to the southern part of the city). Hence, it was decided on this outfall as one separate alternative WWTP site without interconnection with the other outfalls.

The next question addressed was whether, for the remaining 4 outfalls, the WWTP needed to be constructed at 1 location, such that wastewaters from other locations could be transferred to a common place, or whether WWTPs should be constructed at multiple locations. This led to formulation of multiple combinations of alternatives for the evaluation. Various possible combinations of alternatives were formulated by changing the 


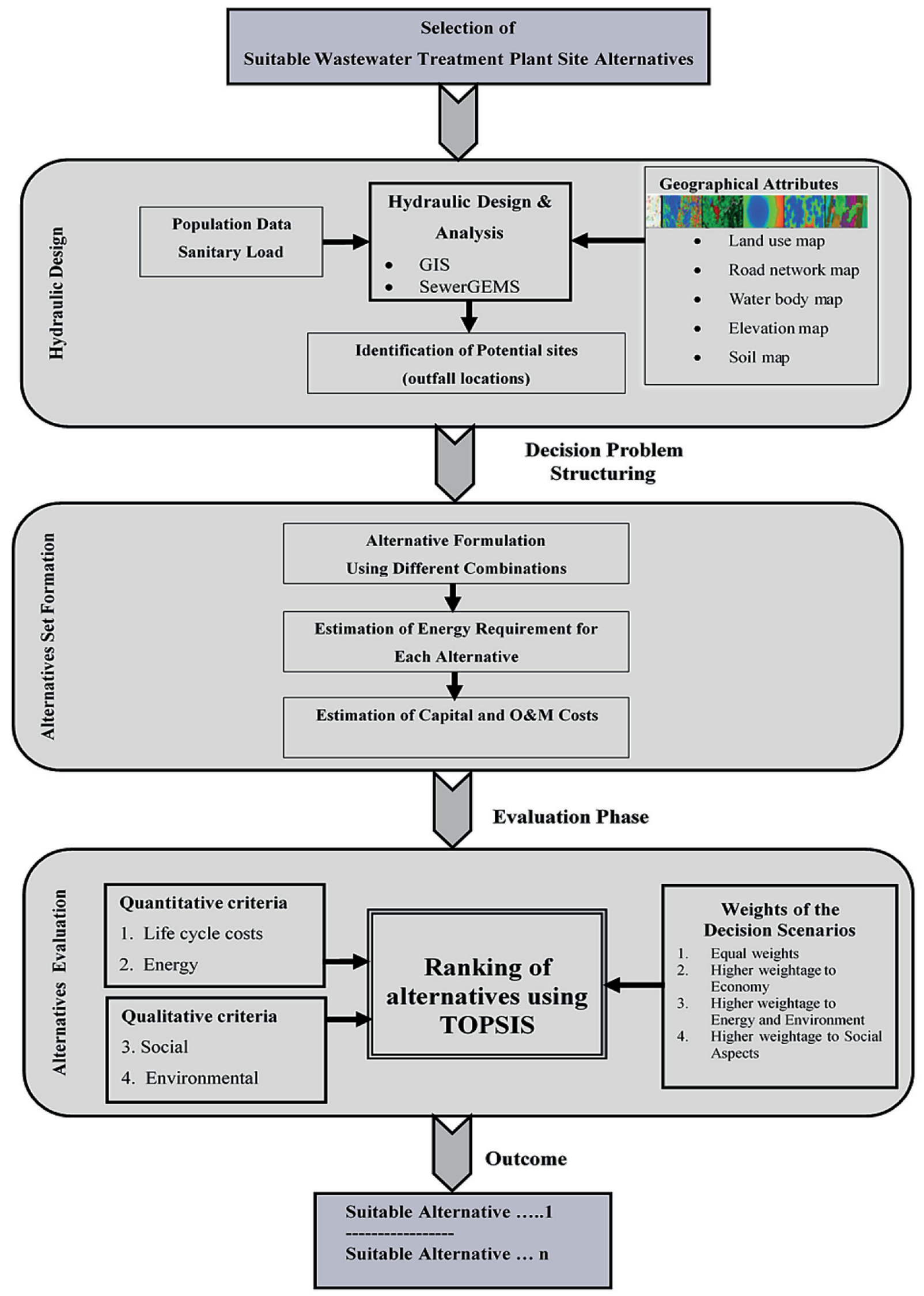

Figure 1

Framework on GIS based AHP-TOPSIS approach for WWTP site selection 


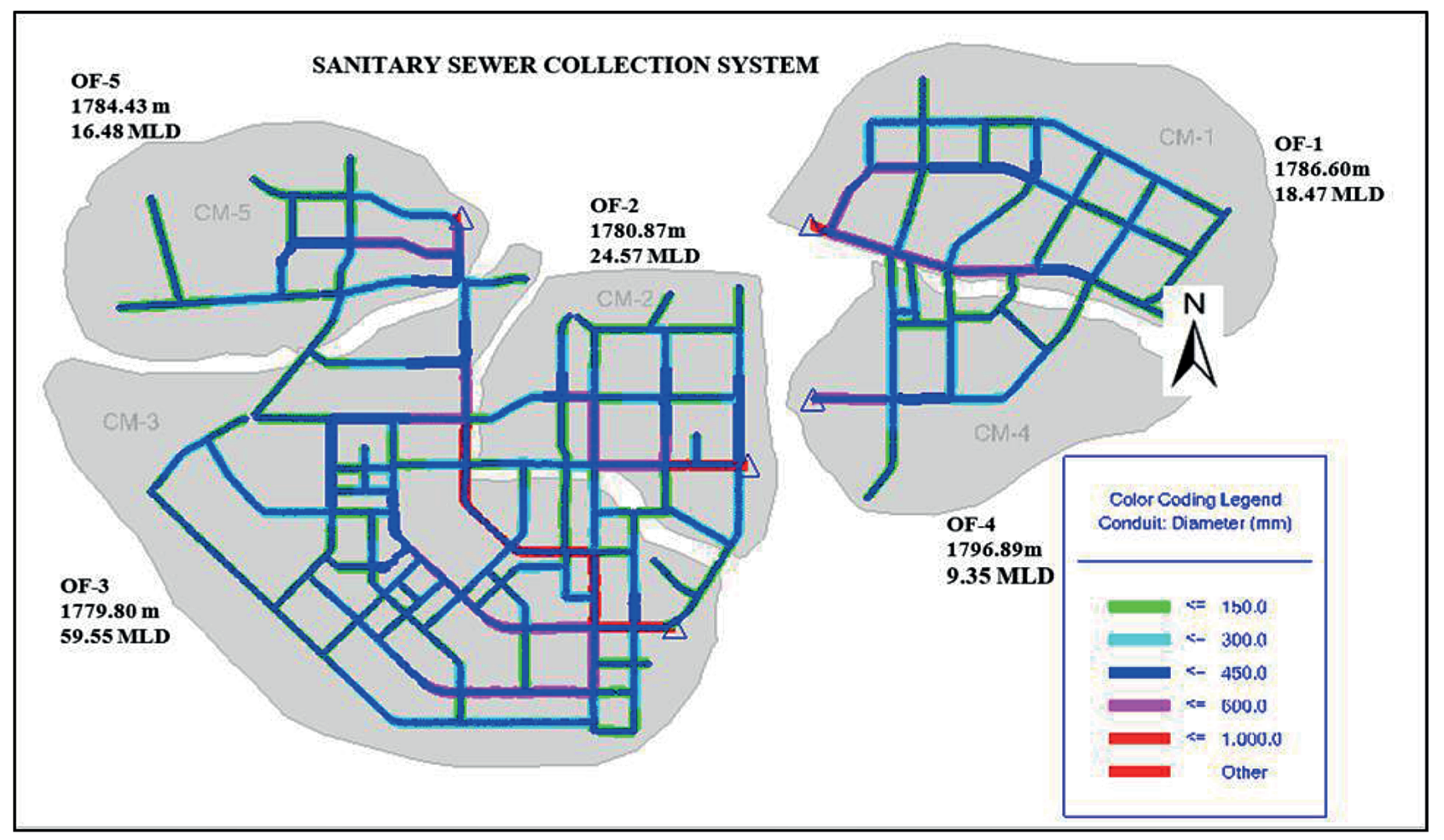

Figure 2

Designed sanitary sewer collection system and associated drainage zones

number of WWTPs and locations. Table 2 shows the list of 15 possible alternatives and corresponding cost analyses.

Key data used for the estimation of cost shown in Table 2 are projected sanitary load/flow rate, pumping time, total pumping head and electricity cost. The inter-location transfer path from one outfall to the other is decided by the minimum cost approach. Hence, all 15 alternatives listed in Table 2 are the most practically feasible alternatives requiring minimum energy and minimum capital costs. Rigorous field information about all 4 outfall locations was obtained through field visits and data collection. Table 3 thus shows the information gathered on the 4 locations, which helped in formulation of alternatives and understanding the operation of these alternatives.

\section{Criteria and indicators}

Various aspects need to be taken into account for selecting the site for a WWTP. Apart from technical feasibility, the three dimensions of sustainability need to be considered as well. Various sustainability criteria and indicators such as technical efficiency, minimization of environmental impacts and health risks, cost efficiency, public participation and acceptability have been proposed and applied for the site selection problem (Azar, 2000; Benedetti et al., 2010; Flores-Alsina et al., 2008; Sharifi and Retsios, 2004; Sumathi et al., 2008; Yoon and Hwang, 1995; Zhao and Yang, 2009). Based on the comprehensive literature review and considering the available data, 4 criteria were selected to rank wastewater treatment plant site alternatives. Each of the criteria has one or more indicators (attributes) shown in Table 4.
The energy consumption requirements for each alternative were estimated using design flow rates, hydraulic design results and downturn levels of the outfall locations. The energy required for local pumping, meaning wastewater transfer from outfall invert level to WWTP inlet level was estimated using dynamic hydraulic head difference available from hydraulic designs. Similarly, energy required for inter-location transfer, meaning transfer of wastewater from one outfall location to another (for example, in Alternative 6 in Table 2, wastewater needs to be transferred from OF-3 to OF-2) was estimated. Table A3 (Appendix) provides detailed information about local pumping energy and inter-location transfer energy requirements for all 15 possible alternatives.

Further, it was assumed that energy required for WWTP operation is $25 \%$ of the total energy required for pumping (Kadar and Siboni, 1998; Michel et al., 1969; Tsagarakis et al., 2003). The sum of local pumping, inter-location transfer and WWTP operation energy requirement in $\mathrm{kWh} / \mathrm{yr}$ was used as an indicator representing criteria for energy consumption. Table 5 shows the summarized score for all alternatives and criteria.

Economic criteria expressed as net present value (NPV) were quantified as per the present worth method, prescribed in the Indian Standards (BIS, 1994). NPV accounts for both capital costs and operation and maintenance (O\&M). The capital costs included the cost incurred for civil works, electromechanical equipment and the cost of land. It was assumed that capital costs are $25 \%$ of total operational costs required for the particular alternative (Kadar and Siboni, 1998; Michel et al., 1969; Müller, 2003; Tsagarakis et al., 2003). O\&M costs included electrical energy costs required to operate the WWTP, inter-location transfer, local pumping, labour costs, 


\begin{tabular}{|c|c|c|c|c|c|c|c|c|}
\hline \multicolumn{9}{|c|}{$\begin{array}{c}\text { TABLE } 2 \\
\text { Possible alternatives and corresponding cost analyses }\end{array}$} \\
\hline $\begin{array}{l}\text { Alternative } \\
\text { No. }\end{array}$ & $\begin{array}{c}\text { STP } \\
\text { alternatives }\end{array}$ & $\begin{array}{l}\text { Local } \\
\text { pumping-OF }\end{array}$ & $\begin{array}{c}\text { Inter } \\
\text { location } \\
\text { transfer-OF }\end{array}$ & $\begin{array}{l}\text { Inter location } \\
\text { transfer } \\
\text { (USD/yr) }\end{array}$ & $\begin{array}{l}\text { Local } \\
\text { pumping } \\
\text { (USD/yr) }\end{array}$ & $\begin{array}{l}\text { Capital } \\
\text { cost }\end{array}$ & \begin{tabular}{|c|} 
STP O\&M cost \\
(USD/yr $-19 \%$ of total \\
operating cost)
\end{tabular} & $\begin{array}{c}\text { Miscellaneous } \\
\text { (USD/yr }-5 \% \text { of total } \\
\text { operating cost) }\end{array}$ \\
\hline \multirow{4}{*}{1} & \multirow{4}{*}{$\begin{array}{l}\text { WWTP at } \\
\text { all } 4 \text { locations }\end{array}$} & OF-1 & & & 172141 & 43035 & 32707 & 8607 \\
\hline & & OF-2 & & & 229001 & 57250 & 43510 & 11450 \\
\hline & & OF-3 & & & 555114 & 138778 & 105472 & 27756 \\
\hline & & OF-4 & & & 87134 & 21783 & 16555 & 4357 \\
\hline & NPV & & & & 8183446 & 2045861 & 1554855 & 409172 \\
\hline \multirow{3}{*}{2} & \multirow{3}{*}{ WWTP at OF-1 } & OF-1 & OF-2 & 305118 & 172141 & 119315 & 90679 & 23863 \\
\hline & & OF-1 & OF-3 & 884558 & 172141 & 264175 & 200773 & 52835 \\
\hline & & OF-1 & OF-4 & 58117 & 172141 & 57565 & 43749 & 11513 \\
\hline & NPV & & & 9786616 & 4050380 & 3459249 & 2629029 & 691850 \\
\hline \multirow{3}{*}{3} & \multirow{3}{*}{ WWTP at OF-2 } & OF-2 & OF-1 & 112294 & 229001 & 85324 & 64846 & 17065 \\
\hline & & OF-2 & OF-3 & 325642 & 229001 & 138661 & 105382 & 27732 \\
\hline & & OF-2 & OF-4 & 51115 & 229001 & 138661 & 105382 & 27732 \\
\hline & NPV & & & 3835699 & 5388253 & 2844278 & 2161651 & 568856 \\
\hline \multirow{3}{*}{4} & \multirow{3}{*}{ WWTP at OF-3 } & OF-3 & OF-1 & 130836 & 555114 & 151557 & 115183 & 30311 \\
\hline & & OF-3 & OF-2 & 156820 & 555114 & 177983 & 135267 & 35597 \\
\hline & & OF-3 & OF-4 & 65530 & 555114 & 155161 & 117922 & 31032 \\
\hline & NPV & & & 2770086 & 13061500 & 3801581 & 2889202 & 760316 \\
\hline \multirow{3}{*}{5} & & OF-4 & OF-1 & 281674 & 87134 & 38166 & 29006 & 7633 \\
\hline & WWTP at OF-4 & OF-4 & OF-2 & 503061 & 87134 & 147549 & 112137 & 29510 \\
\hline & & OF-4 & OF-3 & 1369192 & 87134 & 364081 & 276702 & 72816 \\
\hline & NPV & & & 16893546 & 2050204 & 4312126 & 3277216 & 862425 \\
\hline & & OF-1 & & & & & & \\
\hline & WWTP at & OF-2 & OF-3 & 432750 & 229001 & 165438 & 125733 & 33088 \\
\hline 6 & OF-1 \& OF-2 & OF-1 & & & & & & \\
\hline & & OF-2 & OF-4 & 51115 & & 12779 & 9712 & 2556 \\
\hline & NPV & & & 3795014 & 1796084 & 1397775 & 1062309 & 279555 \\
\hline & & OF-1 & $\mathrm{OF}_{\mathrm{S}}$ & & & & & \\
\hline & WWTP at & OF-3 & $\mathrm{OF}-2$ & 156820 & 555114 & 177983 & 135267 & 35597 \\
\hline 7 & OF-1 \& OF-3 & OF-1 & & & & & & 11513 \\
\hline & & OF-3 & $\mathrm{OF}-4$ & 58117 & 172141 & 57565 & 43749 & \\
\hline & NPV & & & 1685787 & 5703960 & 1847437 & 1404052 & 369487 \\
\hline & & OF-1 & & 305118 & 444091 & 187302 & 142350 & 37460 \\
\hline 8 & WWTP at & OF-4 & $\mathrm{OF}-2$ & & & & & \\
\hline 8 & OF-1 \& OF-4 & OF-1 & $\mathrm{OF}_{3} 3$ & 884558 & & 221140 & 168066 & 44228 \\
\hline & & OF-4 & $\mathrm{OF}-3$ & & & & & \\
\hline & NPV & & & 9330792 & 3483067 & 3203465 & 2434633 & 640693 \\
\hline & & OF-2 & & & & & & \\
\hline 0 & WWTP at & OF-3 & OF1 & 104754 & 555114 & 164967 & 125375 & 32993 \\
\hline 9 & OF-2 \& OF-3 & OF-2 & & 51115 & 229001 & 70029 & 53222 & 14006 \\
\hline & & OF-3 & $\mathrm{OF}-4$ & & & & & \\
\hline & NPV & & & 1222499 & 6149918 & 1843104 & 1400759 & 368621 \\
\hline & & OF-2 & OF-1 & 112294 & 229001 & 85324 & 64846 & 17065 \\
\hline 10 & WWTP at & OF-4 & & & & & & \\
\hline 10 & OF-2 \& OF-4 & OF-2 & OF-3 & 432750 & & 108187 & 82222 & 21637 \\
\hline & & OF-4 & & & & & & \\
\hline & NPV & & & 4274857 & 1796084 & 1517735 & 1153479 & 303547 \\
\hline & & OF-3 & $\mathrm{OF}_{1}$ & 104754 & 555114 & 137211 & 104281 & 27442 \\
\hline 11 & WWTP at & OF-4 & $\mathrm{OF}-1$ & & & & & \\
\hline 11 & OF-3 \& OF-4 & OF-3 & $\mathrm{OF}_{\mathrm{S}}$ ? & 156820 & & 39205 & 29796 & 7841 \\
\hline & & OF-4 & $\mathrm{OF}-2$ & & & & & \\
\hline & NPV & & & 2051563 & 4353833 & 1383657 & 1051580 & 276731 \\
\hline & & OF-1 & & & & & & \\
\hline 12 & WWTP at $\mathrm{OF}-1$ & OF-2 & $\mathrm{OF}-4$ & 51115 & 229001 & 70029 & 53222 & 14006 \\
\hline & & OF-3 & & & & & & \\
\hline & NPV & & & 400899 & 1796084 & 549246 & 417427 & 109849 \\
\hline & & OF-1 & & & & & & \\
\hline 13 & WW TP at OF-1. & OF-2 & OF-3 & 432750 & 229001 & 165438 & 125733 & 33088 \\
\hline & & OF-4 & & & & & & \\
\hline & NPV & & & 3394115 & 1796084 & 1297550 & 986138 & 259510 \\
\hline & & OF-1 & & & & & & \\
\hline 14 & WW $1 P$ at $U F-1$. & OF-3 & OF-2 & 156820 & 555114 & 177983 & 135267 & 35597 \\
\hline & & OF-4 & & & & & & \\
\hline & NPV & & & 1229963 & 4353833 & 1395949 & 1060921 & 279190 \\
\hline & & OF-2 & & & & & & \\
\hline 15 & WW 1 a a $O F-2$. & OF-3 & & 104754 & 555114 & 164967 & 125375 & 32993 \\
\hline & & OF-4 & & & & & & \\
\hline & NPV & & & 821600 & 4353833 & 1293858 & 983332 & 258772 \\
\hline
\end{tabular}




\begin{tabular}{|c|c|c|}
\hline \multicolumn{3}{|c|}{$\begin{array}{c}\text { TABLE } 3 \\
\text { Site information collected through field visits and } \\
\text { municipal authority records }\end{array}$} \\
\hline Outfall & Area (ha) & Surrounding plots \\
\hline \multirow{7}{*}{ OF-1 } & 7.00 & Agricultural plots - horticulture \\
\hline & 3.25 & Administration \\
\hline & 16.04 & Public service \\
\hline & 14.68 & Formal green \\
\hline & 0.75 & Recreation - open space \\
\hline & 10.20 & Lake Tana \\
\hline & 0.48 & Commercial centr \\
\hline \multirow{5}{*}{ OF-2 } & 60.18 & Open ditch/flood-prone area \\
\hline & 26.29 & Forest \& informal green \\
\hline & 19.17 & Conservation area \\
\hline & 14.52 & Commercial activities \\
\hline & $\begin{array}{l}17600 \mathrm{~m} \\
\text { length }\end{array}$ & Blue Nile River \\
\hline \multirow{6}{*}{ OF-3 } & 13.42 & Conservation area \\
\hline & 36.19 & Open space \\
\hline & 102.3 & Agricultural and informal green \\
\hline & 27.95 & Manufacturing and storage \\
\hline & 17.04 & $\begin{array}{l}\text { Residential area (peri-urban area } \\
\text { far from outfall site, about } 1.5 \mathrm{~km} \text { ) }\end{array}$ \\
\hline & $\begin{array}{l}17600 \mathrm{~m} \\
\text { length }\end{array}$ & Blue Nile River \\
\hline \multirow{5}{*}{ OF-4 } & 31.99 & Recreation - formal green \\
\hline & $\begin{array}{c}17600 \mathrm{~m} \\
\text { length }\end{array}$ & Blue Nile River \\
\hline & 6.87 & Agricultural - horticulture \\
\hline & 19.30 & Forest and informal green \\
\hline & 2.25 & Recreation - resort centres \\
\hline
\end{tabular}

spare parts and maintenance costs. It was assumed that O\&M costs are $19 \%$ and miscellaneous costs are $5 \%$ of the total operational costs (Kadar and Siboni, 1998; Michel et al., 1969; Müller, 2003; Tsagarakis et al., 2003).

Social criteria are often neglected from decision making for site selection. However, this is one of the important criteria as it considers compatibility of the facility in terms of the distance from human settlement, public benefit and mitigation of impacts to the host community, by evaluating the present and anticipated future use of the surrounding area where the new site is proposed (Lober, 1995). As shown in Table 4, in this study 3 indicators were used for incorporating social issues in the WWTP site selection problem.

Land acquisition is one of the major challenges in any developmental project. Hence, it is important to consider this indicator in decision making. Land use permitting or zoning shall be compatible with the host neighbourhood and sufficiently flexible to enable opportunities for vehicle movement and infrastructure development. Furthermore, this indicator has focused on change from existing use and minimal displacement of housing and businesses. Each community has a different culture, attitudes, and habits for the reuse of waste and sanitation and hence acceptability is a crucial socio-economic factor for the selection of a WWTP site. In this study the acceptability indicator represents these social acceptance issues along with aesthetics of the surrounding area and distance from the residential zones and public buildings (schools, hospitals).

The third indicator in social criteria incorporates the issues of local development and creation of public participation. This is one of the important aspects to make any developmental project successful. If the local development goes hand-in-hand with infrastructure development projects, then the projects will become successful on a social front, with enhanced sustainability.

The local environmental aspect is an important consideration in any site selection problem. Environmental criteria cover surface water and groundwater quality, land cover and ecological character, site management and public health (Paul, 2012; SAHC, 1998; Sumathi et al., 2008). In this

\begin{tabular}{|c|c|c|c|c|c|c|}
\hline \multicolumn{7}{|c|}{$\begin{array}{c}\text { TABLE } 4 \\
\text { Criteria with respective indicators used for selection of WWTP site }\end{array}$} \\
\hline \multirow[b]{2}{*}{ No. } & \multirow[b]{2}{*}{ Criteria } & \multirow[b]{2}{*}{ Indicator } & \multicolumn{4}{|c|}{ Weights } \\
\hline & & & Equal weights & $\begin{array}{l}\text { Higher weighting } \\
\text { to economy }\end{array}$ & $\begin{array}{l}\text { Higher weighting } \\
\text { to energy and } \\
\text { environment }\end{array}$ & $\begin{array}{c}\text { Higher } \\
\text { weighting to } \\
\text { social aspects }\end{array}$ \\
\hline 1 & $\begin{array}{l}\text { Economic (life cycle } \\
\text { costs) }\end{array}$ & $\begin{array}{l}\text { Net present value } \\
(\text { USD })^{1}\end{array}$ & 0.333 & 0.600 & 0.200 & 0.200 \\
\hline 2 & $\begin{array}{l}\text { Energy } \\
\text { consumption }^{2}\end{array}$ & $\begin{array}{l}\text { Energy } \\
\text { consumption } \\
(\mathrm{kWh} / \mathrm{yr})\end{array}$ & 0.167 & 0.200 & 0.300 & 0.100 \\
\hline \multirow[b]{3}{*}{3} & \multirow[b]{3}{*}{ Social } & Land acquisition & 0.111 & 0.033 & 0.067 & 0.200 \\
\hline & & Acceptability & 0.111 & 0.033 & 0.067 & 0.200 \\
\hline & & $\begin{array}{l}\text { Local } \\
\text { development } \\
\text { \& public } \\
\text { participation }\end{array}$ & 0.111 & 0.033 & 0.067 & 0.200 \\
\hline 4 & Environmental & $\begin{array}{l}\text { Water quality } \\
\text { deterioration }\end{array}$ & 0.167 & 0.100 & 0.300 & 0.100 \\
\hline
\end{tabular}

Note 1: Net present value comprises the capital costs and O\&M costs (inter-location pumping, local pumping and miscellaneous costs) Note 2: Energy consumption includes inter-location pumping, local pumping and WWTP operating energy 
TABLE 5

Indicator scores for the $\mathbf{1 5}$ alternatives

\begin{tabular}{|l|c|c|c|c|c|c|}
\hline \multirow{2}{*}{ Alternatives } & \multicolumn{6}{|c|}{ Criteria } \\
\cline { 2 - 7 } & $\begin{array}{c}\text { Energy } \\
\text { (kWh/year) }\end{array}$ & $\begin{array}{c}\text { NPV } \\
\text { (USD) }\end{array}$ & $\begin{array}{c}\text { Land } \\
\text { acquisition }\end{array}$ & Acceptability & $\begin{array}{c}\text { Local development \& } \\
\text { public participation }\end{array}$ & $\begin{array}{c}\text { Water quality } \\
\text { deterioration }\end{array}$ \\
\hline $\mathbf{1}$ & 21644487 & 12193334 & 900 & 500 & 400 & 800 \\
\hline $\mathbf{2}$ & 36509272 & 20617124 & 750 & 350 & 300 & 700 \\
\hline $\mathbf{3}$ & 26576519 & 14798736 & 600 & 500 & 450 & 100 \\
\hline $\mathbf{4}$ & 42632663 & 23282685 & 300 & 650 & 600 & 100 \\
\hline $\mathbf{5}$ & 50178410 & 27395518 & 650 & 400 & 300 & 200 \\
\hline $\mathbf{6}$ & 14806028 & 8330737 & 675 & 425 & 375 & 400 \\
\hline $\mathbf{7}$ & 19549064 & 11010723 & 525 & 500 & 450 & 400 \\
\hline $\mathbf{8}$ & 28231192 & 19092649 & 750 & 350 & 300 & 700 \\
\hline $\mathbf{9}$ & 19502202 & 10984901 & 450 & 575 & 525 & 100 \\
\hline $\mathbf{1 0}$ & 20719885 & 9045702 & 600 & 500 & 450 & 100 \\
\hline $\mathbf{1 1}$ & 16938692 & 9117365 & 300 & 650 & 600 & 100 \\
\hline $\mathbf{1 2}$ & 5780731 & 3273505 & 600 & 500 & 450 & 100 \\
\hline $\mathbf{1 3}$ & 13723325 & 7733398 & 600 & 500 & 450 & 100 \\
\hline $\mathbf{1 4}$ & 14794505 & 8319857 & 300 & 650 & 600 & 100 \\
\hline $\mathbf{1 5}$ & 13721471 & 7711396 & 300 & 650 & 600 & 100 \\
\hline Type of criteria & Cost & Cost & Cost & Benefit & Benefit & Cost \\
\hline
\end{tabular}

study, due to data availability considerations, deterioration of local water resources quality is considered as an indicator. The selected wastewater treatment plant site alternatives might discharge the treated or untreated wastewater, i.e., overflow sewage into the neighbouring water body. This particular attribute attempts to account for the proximity to groundwater and surface water, reclaimed water to river outfall, and potential raw sewage discharge into the water.

As is evident from the list of indicators in Table 5, the indicators NPV and energy consumption are quantitative. The indicators accounting for social and environmental issues are qualitative. Hence, a different approach is needed to quantify the qualitative indicators. Land acquisition, acceptability, local development and public participation, and water quality deterioration were quantified using a cardinal scale (1-1 000) based on authors' field visits, expertise sought, discussion with municipal authorities and native knowledge about Bahir Dar City (Table 3).

\section{Weight elicitation}

Weighing is an important part of MADM, which affects the results. Weight elicitation can be carried out using various approaches. Use of direct rating using cardinal scales or the AHP method is common (Saaty, 1980; Saaty, 1990) for weight elicitation. Direct rating was adopted in this study for weight elicitation. Also, it is important to structure the decision problem correctly (formulation of scenarios) to obtain stable ranking results using MADM (Kalbar et al., 2012). Hence, in this study, as shown in Table 6, we used 4 sets of weights representing 4 scenarios. The 4 scenarios include equal weights to 3 criteria (economy, energy and environment and social issues), higher weight to economy, higher weight to energy and environment and higher weight to social issues. Considering these 4 scenarios, weight elicitation using a direct rating method was carried out for all the indicators.

\section{Ranking of alternatives with TOPSIS}

Many MADM methods are available for ranking the alternatives (Yoon and Hwang, 1995). In the context of environmental decision making TOPSIS has been used as the most suitable method for evaluation of alternatives (Kalbar et al., 2012). The ability of TOPSIS to consider positive and negative aspects of the alternative simultaneously makes the method more suitable for environmental problems. The intuitive nature of human thinking to strike the balance between cost and benefit types of indicators is mimicked in TOPSIS. Hence, TOPSIS has been chosen for the ranking in this study. The detailed method and theory behind TOPSIS is described in Kalbar et al. (2012).

\section{RESULTS AND DISCUSSION}

Site selection problem for WWTP are addressed in this study. This complex decision-making problem is structured in 3 layers. First, the hydraulically feasible WWTP locations (outfalls) were identified using GIS-based hydraulic design. Then, all the practically possible combinations were worked out in order to formulate the set of 15 possible alternatives. Finally, these 15 alternatives were evaluated using the MADM method in order to identify the best alternative.

Results of the ranking using the TOPSIS method are presented in Table 6 . Thus, for the 3 scenarios, Alternative 12 (WWTP at OF-1, OF-2 and OF-3) was identified as the best alternative. Further, it is interesting to note that Alternative 15 is ranked as $2^{\text {nd }}$ in the first 3 scenarios. For the scenario 


\begin{tabular}{|l|c|c|c|c|c|c|c|c|}
\hline \multicolumn{7}{|c|}{ Results of the ranking using TOPSIS methodology } \\
\hline \multicolumn{2}{|c|}{ Equal weights } & \multicolumn{2}{c|}{$\begin{array}{c}\text { Higher weighting } \\
\text { to economy }\end{array}$} & \multicolumn{2}{c|}{$\begin{array}{c}\text { Higher weighting } \\
\text { to energy and environment }\end{array}$} & \multicolumn{2}{c|}{$\begin{array}{c}\text { Higher weighting to social } \\
\text { aspects }\end{array}$} \\
\hline Rank & Alternatives & Score & Alternatives & Score & Alternatives & Score & Alternatives & Score \\
\hline 1 & A12 & 0.9044 & A12 & 0.9797 & A12 & 0.9493 & A15 & 0.8672 \\
\hline 2 & A15 & 0.8438 & A15 & 0.8202 & A15 & 0.8730 & A14 & 0.8500 \\
\hline 3 & A14 & 0.8231 & A13 & 0.8183 & A13 & 0.8636 & A11 & 0.8253 \\
\hline 4 & A13 & 0.8152 & A14 & 0.7957 & A14 & 0.8566 & A12 & 0.7670 \\
\hline 5 & A11 & 0.7934 & A6 & 0.7805 & A11 & 0.8278 & A9 & 0.7334 \\
\hline 6 & A10 & 0.7579 & A11 & 0.7619 & A9 & 0.7857 & A13 & 0.7181 \\
\hline 7 & A9 & 0.7283 & A10 & 0.7538 & A10 & 0.7831 & A10 & 0.6850 \\
\hline 8 & A6 & 0.7131 & A9 & 0.6886 & A3 & 0.6903 & A7 & 0.6323 \\
\hline 9 & A7 & 0.6541 & A7 & 0.6765 & A6 & 0.6771 & A6 & 0.6055 \\
\hline 10 & A3 & 0.5998 & A1 & 0.6060 & A7 & 0.6314 & A3 & 0.5761 \\
\hline 11 & A1 & 0.4929 & A3 & 0.5367 & A4 & 0.5326 & A4 & 0.5171 \\
\hline 12 & A4 & 0.4118 & A8 & 0.3553 & A5 & 0.4375 & A1 & 0.4310 \\
\hline 13 & A8 & 0.3312 & A2 & 0.2801 & A1 & 0.3915 & A5 & 0.3012 \\
\hline 14 & A5 & 0.3003 & A4 & 0.2315 & A8 & 0.3283 & A8 & 0.2959 \\
\hline 15 & A2 & 0.2586 & A5 & 0.1326 & A2 & 0.2366 & A2 & 0.2394 \\
\hline
\end{tabular}

in which a higher weighting was given to the social criteria, Alternative 15 was identified as the best one.

The preference for Alternative 12 can be justified in the context of site-specific information given in Table 3. The site-specific information reveals that the relative open area available at each of the outfalls varies drastically. The outfalls (OF-1 to OF-4) have relative open areas of $12 \%, 28 \%$, $46 \%$ and $14 \%$, respectively. Hence, the results of ranking match with the advantages and disadvantages posed by the locations of each site. Selection of Alternative 12 implies that all the wastewater collected at OF-4 (9.35 MLD) shall be transferred to OF-2 and a bigger WWTP constructed of about 33.92 MLD capacity at OF-2, which is feasible looking at the $28 \%$ of relative open area at OF-2. Similarly, a bigger WWTP can be constructed at OF-3, if Alternative 15 is implemented. In any case, the evaluation of alternatives shows that a WWTP at OF-4 should not be implemented, the reasons for this being the small surrounding area near OF-4 and low wastewater flow. Also, it seems logical that as the wastewater quantity collected at OF- 4 is small it can be easily transferred to a nearer outfall, which is evident from the ranking results.

Additionally, Alternative 2 is ranked $15^{\text {th }}$ for 3 scenarios, showing that constructing a single large WTTP at OF-1 is not at all desirable. This can be due to the sensitive local social and environmental conditions. Alternative 5 ranked lowest of the scenarios where higher weighting to economy was given. This justifies that as the wastewater flows at other outfall locations are high, transferring wastewater from these outfalls to OF-4 will not be economical. Overall it was found that constructing a large WWTP at OF-1 and OF-4 is not feasible from social, economic and environmental perspectives.

Hence, the choice of Alternative 12 (constructing WWTPs at OF-1, OF-2 and OF-3 by transferring wastewater flow from OF-4 to OF-2) is the most appropriate strategy which matches the local conditions. In order to examine the robustness of the final results regarding the selection of a wastewater treatment plant site, sensitivity analysis was elicited for each of the criteria and indicators with respect to alternatives. It is indispensable to analyse how each criterion affects the ranking of alternatives and to determine the weight range within which the ranking will not change. It can be noted from Table 7 that Alternative 5 (with the threshold value of $-10.02 \%$ ) has the minimum global criticality degree among the alternatives in the equal weight scenario for a particular economic indicator (inter-location transfer cost).

This implies that Alternative 5 is the most sensitive alternative in the equal weight scenario, and a relative increase of more than $10.02 \%$ in this indicator will affect the ranking and will lead to swapping the rank of Alternative 5 with Alternative 14. Additionally, the sensitivity coefficient for Alternative 5 is the highest, which indicates that Alternative 5 is the most sensitive alternative to the respective criterion as is clearly shown in Fig. 3. The figure also shows that the rank of Alternative 12 is not sensitive to any of the criteria and thus its rank will not change.

Although the results from the present study are interesting and reflect correctly on the field situation, there are some limitations of the study that need to be taken into account when using the results in further applications. Some gross assumptions were made while making cost estimates for capital costs and O\&M costs.

Additionally, the energy consumption requirement for operation of the plant was assumed based on secondary literature. However, this does not affect the results, as it can be seen that the capital cost investments or O\&M costs will follow the ratio of wastewater quantities to be treated; hence it is envisaged that the results of this preliminary analysis remain unchanged during detailed evaluation. 


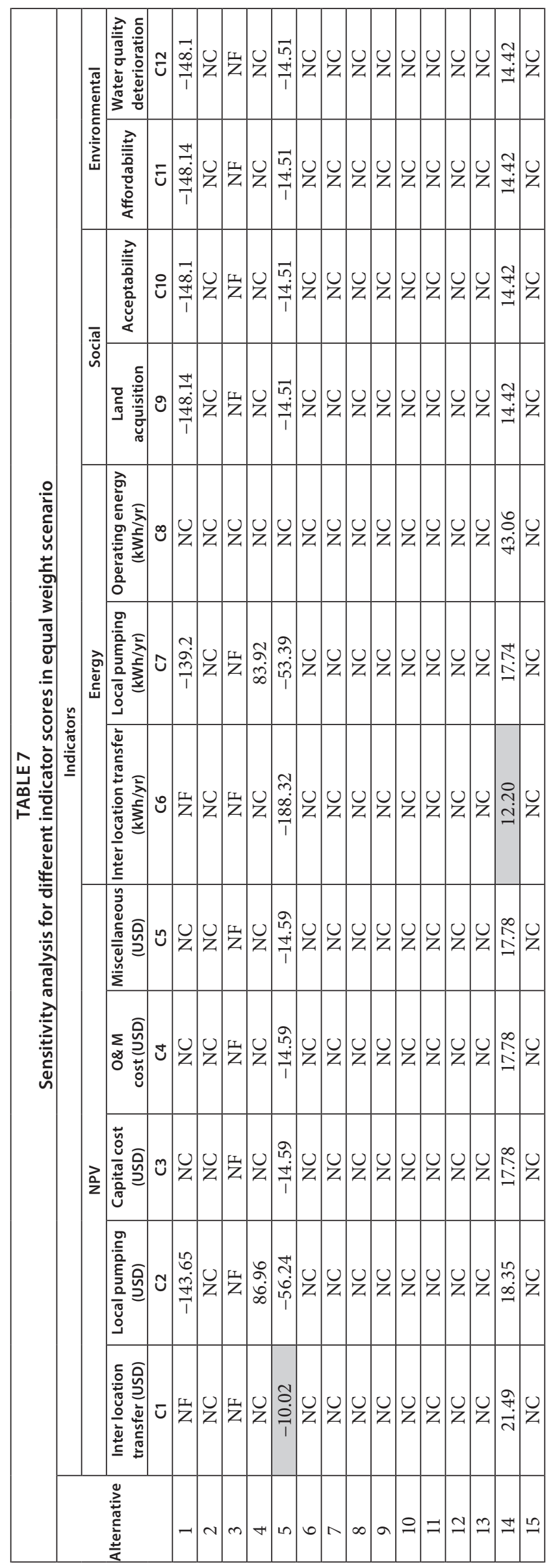

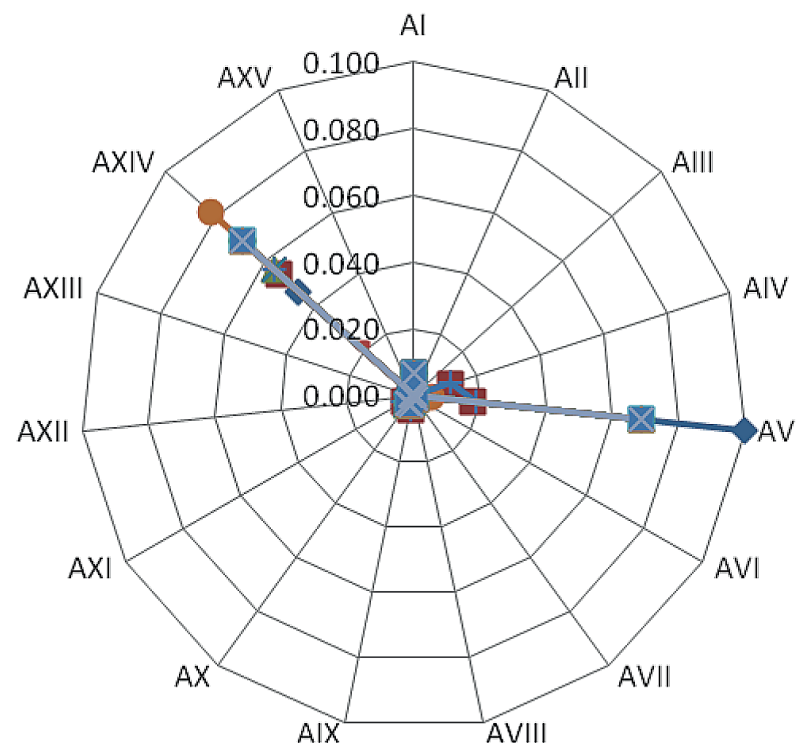

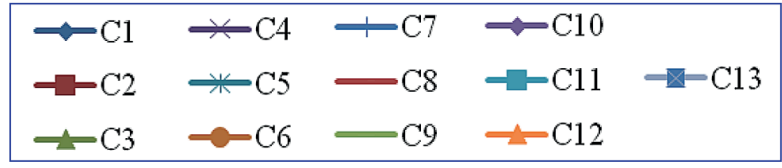

Figure 3

Radar plot showing the most sensitive alternatives for the particular indicators

\section{CONCLUSIONS}

The Bahir Dar City presently lacks water and sanitation infrastructure facilities and is in the phase of planning and development of these facilities. In this context it is highly relevant to take a systemic approach to decision making while planning and designing these facilities. The present study addresses the site selection problem for WTTP at Bahir Dar City.

A three-tiered approach was adopted to solve the complex decision problem of site selection for WWTPs. A GIS-based hydraulic design of the underground sewer system was carried out to identify feasible outfall locations. From these feasible outfall locations, a set of 15 possible alternatives was formulated. These 15 alternatives were evaluated in detail to quantify the economic, environmental and social performance.

The quantified indicators were used to rank these alternatives under various scenarios using MADM methodology (TOPSIS). The results from ranking showed that Alternative 12 (constructing WWTPs at OF-1, OF-2 and OF-3 by transferring wastewater flow from OF-4 to OF-2) is most feasible from all three dimensions of sustainability. The results of ranking also helped to understand that, overall, constructing large WWTP at OF-1 and OF-4 is not feasible from social, economic and environmental perspectives.

The developed decision-making approach is robust and provides a decision support system for municipal authorities of Bahir Dar City. The framework, in future, can be extended further to include choice of wastewater treatment technology in the context of overall planning for the city. 


\section{ACKNOWLEDGEMENTS}

The Scholarship provided by Ethiopian Ministry of Education to Mr Tilik Tena Wondim is highly acknowledged. Mr Wondim also thanks Bahir Dar City Municipality for help provided during data collection and for facilitation of field visits.

\section{REFERENCES}

AZAR FS (2000) Multiattribute decision-making: use of three scoring methods to compare the performance of imaging techniques for breast cancer detection. University of Pennsylvania Department of Computer and Information Science Technical Report No. MS-CIS-00-10,. URL: https://repository.upenn.edu/ cis_reports/119/ (Accessed 14 July 2018).

BANAR M, KOSE BM, OZKAN A and ACAR IP (2007) Choosing a municipal landfill site by analytic network process. Environ. Geol. 52 (4) 747-751. https://doi.org/10.1007/s00254-006-0512-X

BDIDP (2006) Bahir Dar Integrated Development Plan (BDIDP). Federal Urban Planning Institute. Addis Ababa.

BENEDETTI L, DE BAETS B, NOPENS I and VANROLLEGHEM PA (2010) Multi-criteria analysis of wastewater treatment plant design and control scenarios under uncertainty. Environ. Model. Softw. 25 (5) 616-621. https://doi.org/10.1016/j.envsoft.2009.06.003

BUREAU OF INDIAN STANDARDS (BIS) (1994) IS 13174 Indian standard for life cycle costing. Part 2, Methodology. Bureau of Indian Standards, New Delhi.

Central Statistical Agency (CSA) (2006-7) Ethiopia demographic and health survey. CSA Ethiopia, Addis Ababa.

FLORES-ALSINA X, RODRÍGUEZ-RODA I, SIN G and GERNAEY KV (2008) Multi-criteria evaluation of wastewater treatment plant control strategies under uncertainty. Water Res. 42 (17) 4485-4497. https://doi.org/10.1016/j.watres.2008.05.029

HEHECE (2000) The Hygiene and Environmental Health Executive Committee Ethiopia (HEHECE). Ethiopia (No. R/N 16). HEHEHE, Addis Ababa.

JAVAHERI H, NASRABADI T, JAFARIAN M, ROWSHAN G and KHOSHNAM H (2006) Site selection of municipal solid waste landfills using analytical hierarchy process method in a geographical information technology environment in Giroft. Iran. J. Environ. Health, Sci. Eng. 3 (3) 177-184.

KADAR Y and SIBONI G (1998) Optimization of energy economy in the design and operation of wastewater treatment plants. In: Proceedings of the the 17th Congress of the World Energy Council, 9 September 1998, Texas.

KALBAR PP, KARMAKAR S and ASOLEKAR SR (2012) Selection of an appropriate wastewater treatment technology: A scenario-based multiple-attribute decision-making approach. J. Environ. Manage. 113 158-169. https://doi.org/10.1016/j.jenvman.2012.08.025

KUMIE A and ALI A (2005) An overview of environmental health status in Ethiopia with particular emphasis to its organization, drinking water and sanitation: a literature survey. Ethiopian J. Health Dev. 19 (2) 89. https://doi.org/10.4314/ejhd.v19i2.9977

KURT Ü (2014) The fuzzy TOPSIS and generalized Choquet fuzzy integral algorithm for nuclear power plant site selection-a case study from Turkey. J. Nucl. Sci. Technol. 51 (10) 1241-1255. https:// doi.org/10.1080/00223131.2014.918524

LOBER DJ (1995) Resolving the siting impasse: modeling social and environmental locational criteria with a geographic information system. J. Am. Plann. Ass. 61 (4) 482-495. https://doi org/10.1080/01944369508975659

LÜTHI C, MCCONVILLE J and KVARNSTRÖM E (2010) Community-based approaches for addressing the urban sanitation challenges. Int. J. Urban Sustainable Dev. 1 (1-2) 49-63. https://doi. org/10.1080/19463131003654764

MAKROPOULOS C, ARGYROU E, MEMON F and BUTLER D (2007) A suitability evaluation tool for siting wastewater treatment facilities in new urban developments. Urban Water J. 4 (2) 61-78. https://doi.org/10.1080/15730620701336729

MEKONNEN FH (2012) Liquid waste management: the case of Bahir Dar, Ethiopia. Ethiopian J. Health Dev. 26 (1) 49-53.
MICHEL RL, PELMOTER AL and PALANGE RC (1969) Operation and Maintenance of Municipal Waste Treatment Plants. J. Water Pollut. Control Fed. 41 (3) 335-354.

MOE CL and RHEINGANS RD (2006) Global challenges in water sanitation and health. J. Water Health 4 (S1) 41-57. https://doi. org/10.2166/wh.2006.0043

MÜLLER K (2003) Parameters for effective service checking costs and performance in wastewater treatment. European Water Management Online Official Publication of the European Water Association (EWA). Año.

O'LOUGHLIN R, FENTIE G, FLANNERY B and EMERSON PM (2006) Follow-up of a low cost latrine promotion programme in one district of Amhara, Ethiopia: characteristics of early adopters and non-adopters. Trop. Med. Int. Health 11 (9) 1406-1415. https:// doi.org/10.1111/j.1365-3156.2006.01689.x

PAUL S (2012) Location allocation for urban waste disposal site using multi-criteria analysis: A study on Nabadwip Municipality, West Bengal, India. Int. J. Geomatics Geosci. 3 (1) 74.

PEDRERO F, ALBUQUERQUE A, DO MONTE HM, CAVALEIRO V and ALARCÓN JJ (2011) Application of GIS-based multi-criteria analysis for site selection of aquifer recharge with reclaimed water. Resour. Conserv. Recycl. 56 (1) 105-116. https://doi.org/10.1016/j. resconrec.2011.08.003

SAATY T (1980) The Analytic Hierarchy Process. McGraw Hill, New York.

SAATY TL (1990) How to make a decision: the analytic hierarchy process. Eur. J. Oper. Res. 48 9-26. https://doi. org/10.1016/0377-2217(90)90057-I

SAHC (South Australia Health Commission) (1998) Waste control systems-standard for the construction, installation and operation of septic tank systems in South Australia, supplement B: aerobic wastewater treatment systems. SAHC, Adelaide.

SHARIFI MA and RETSIOS V (2004) Site selection for waste disposal through spatial multiple criteria decision analysis. J. Telecommun. Inf. Technol. 3 28-38.

SUMATHI V, NATESAN U and SARKAR C (2008) GIS-based approach for optimized siting of municipal solid waste landfill. Waste Manage. 28 (11) 2146-2160. https://doi.org/10.1016/j. wasman.2007.09.032

SUOMINEN A, SILFVERBERG K and KYYKOSKI A-M (2010) Summary of the Progress Review of the Improvement of selfsufficiency and sustainability in sanitation waste and energy project in Bahir Dar (SAWE): Project Code ETI 23815801.

TESHOME A (2007) Prospects and challenges of water supply and sanitation in Ethiopia with respect to MDGs. In: Proceedings of the Fifth International Conference on the Ethiopian Economy, 7-9 June 2007, Addis Ababa.

TSAGARAKIS K, MARA D and ANGELAKIS A (2003) Application of cost criteria for selection of municipal wastewater treatment systems. Water Air Soil Pollut. 142 (1-4) 187-210. https://doi. org/10.1023/A:1022032232487

WaterAid Ethiopia (2011) Sanitation promotion and household latrine: 30 years 1981-2011: Briefing note - No. 3. WaterAid Ethiopia, Addis Ababa.

WHO/UNICEF (World Health Organisation/United Nations Children's Fund) (2006) Meeting the MDG drinking water and sanitation target: the urban and rural challenge of the decade. WHO/UNICEF, Geneva. ISBN: 9789241563253

WHO/UNICEF (World Health Organisation/United Nations Children's Fund) (2015) Progress on sanitation and drinking water - 2015 update and MDG assessment. WHO/UNICEF, Geneva. ISBN: 9789241509145.

WHO/UNICEF (World Health Organisation/United Nations Children's Fund) (2017) Progress on drinking water, sanitation and hygiene: 2017 update and SDG baselines. World Health Organization and the United Nations Children's Fund. WHO/ UNICEF, Geneva.

YOON KP and HWANG C-L (1995) Multiple Attribute Decision Making: An Introduction. Sage publications, CA.

ZHAO YW and YANG ZF (2009) Integrative fuzzy hierarchical model for river health assessment: A case study of Yong River in Ningbo City, China. Commun. Nonlin. Sci. Num. Simul. 14 (4) 1729-1736. https://doi.org/10.1016/j.cnsns.2007.09.019 


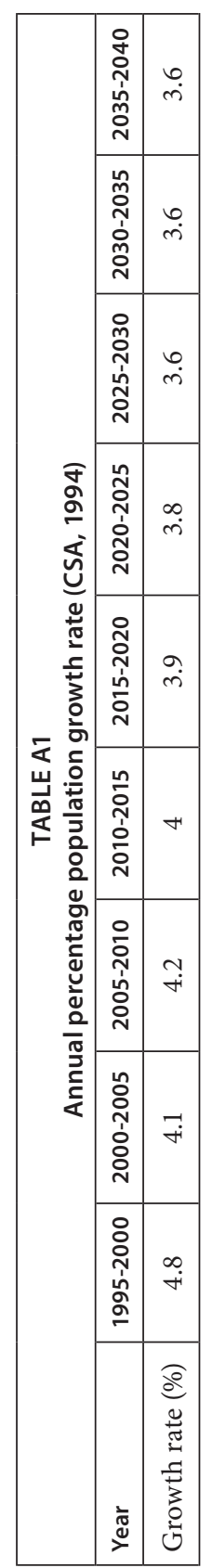

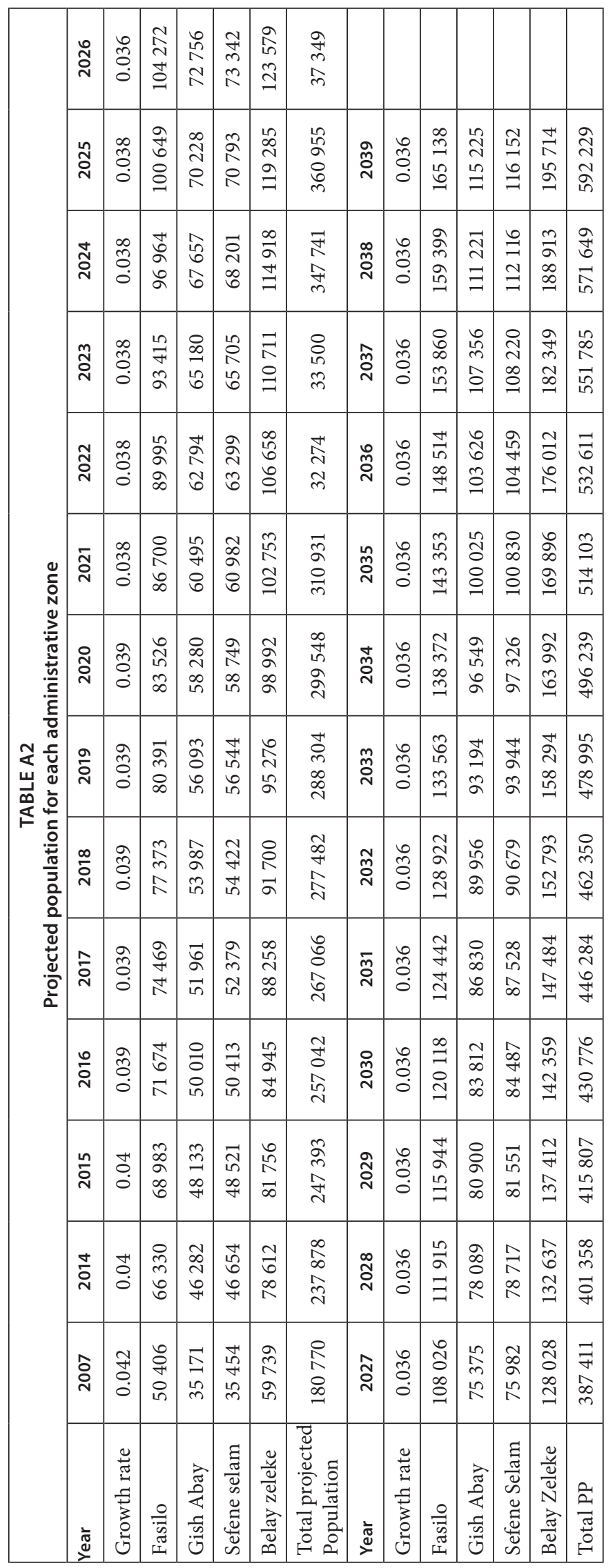




\begin{tabular}{|c|c|c|c|c|c|}
\hline \multicolumn{6}{|c|}{$\begin{array}{l}\text { TABLE } A 3 \\
\text { Energy consumption for each alternatives and corresponding indicators }\end{array}$} \\
\hline Alternatives & $\begin{array}{l}\text { Local pumping } \\
\quad-\text { OF }\end{array}$ & $\begin{array}{l}\text { Inter-location } \\
\text { transfer - OF }\end{array}$ & $\begin{array}{l}\text { Inter-location } \\
\text { transfer (kWh/yr) }\end{array}$ & $\begin{array}{l}\text { Local pumping } \\
\quad(\mathrm{kWh} / \mathrm{yr})\end{array}$ & $\begin{array}{l}\text { STP energy operating } \\
\text { (kWh/yr }-25 \% \text { of total } \\
\text { operating energy) }\end{array}$ \\
\hline \multirow{4}{*}{1} & OF-1 & & & 2818816.88 & 704704.22 \\
\hline & OF-2 & & & 3758422.50 & 939605.63 \\
\hline & OF-3 & & & 9261826.88 & 2315456.72 \\
\hline & OF-4 & & & 1476523.13 & 369130.78 \\
\hline Total energy $(\mathbf{k W h} / \mathbf{y r})$ & & & 0.00 & 17315589.38 & 4328897.34 \\
\hline \multirow{3}{*}{$2(\mathrm{OF}-1)$} & OF-1 & OF-2 & 5007675.56 & 2818816.88 & 1956623.11 \\
\hline & OF-1 & OF-3 & 14758461.51 & 2818816.88 & 4394319.60 \\
\hline & OF-1 & OF-4 & 984829.85 & 2818816.88 & 950911.68 \\
\hline Total energy (kWh/yr) & & & 20750966.91 & 8456450.63 & 7301854.38 \\
\hline \multirow{3}{*}{$3(\mathrm{OF}-2)$} & OF-2 & OF-1 & 1838825.62 & 3758422.50 & 2744664.91 \\
\hline & OF-2 & OF-3 & 7220237.15 & 3758422.50 & 1156146.25 \\
\hline & OF-2 & OF-4 & 866162.49 & 3758422.50 & 1475214.65 \\
\hline Total energy (kWh/yr) & & & 9925225.26 & 11275267.50 & 5376025.81 \\
\hline \multirow{3}{*}{$4(\mathrm{OF}-3)$} & OF-3 & OF-1 & 2142436.09 & 9261826.88 & 2958901.05 \\
\hline & OF-3 & OF-2 & 2573777.32 & 9261826.88 & 2593066.77 \\
\hline & OF-3 & OF-4 & 1110440.20 & 9261826.88 & 3468561.26 \\
\hline Total energy (kWh/yr) & & & 5826653.61 & 27785480.63 & 9020529.08 \\
\hline \multirow{3}{*}{$5(\mathrm{OF}-4)$} & OF-4 & OF-1 & 4612418.17 & 1476523.13 & 6080221.56 \\
\hline & OF-4 & OF-2 & 8256377.42 & 1476523.13 & 4058746.16 \\
\hline & OF-4 & OF-3 & 22844363.13 & 1476523.13 & 2174190.07 \\
\hline Total energy $(\mathbf{k W h} / \mathbf{y r})$ & & & 35713158.72 & 4429569.38 & 12313157.79 \\
\hline \multirow{4}{*}{$6(\mathrm{OF}-1 \&$ OF-2) } & OF-1 & \multirow{2}{*}{ OF-3 } & & 2818816.88 & 921244.84 \\
\hline & OF-2 & & 7220237.15 & 3758422.50 & 2191524.51 \\
\hline & OF-1 & \multirow{2}{*}{ OF-4 } & & 2818816.88 & 1348148.55 \\
\hline & OF-2 & & 866162.49 & 3758422.50 & 1185813.09 \\
\hline Total energy (kWh/yr) & & & 8086399.64 & 13154478.75 & 5646730.99 \\
\hline \multirow{4}{*}{7 (OF-1 \& OF-3) } & OF-1 & \multirow{2}{*}{ OF-2 } & & 2818816.88 & 1956623.11 \\
\hline & OF-3 & & 2573777.32 & 9261826.88 & 4379551.07 \\
\hline & OF-1 & \multirow{2}{*}{ OF-4 } & 984829.85 & 2818816.88 & 4394319.60 \\
\hline & OF-3 & & & 9261826.88 & 8026547.50 \\
\hline Total energy $(\mathrm{kWh} / \mathrm{yr})$ & & & 3558607.17 & 24161287.50 & 18757041.28 \\
\hline \multirow{4}{*}{$8(\mathrm{OF}-1 \&$ OF-4) } & OF-1 & \multirow{2}{*}{$\mathrm{OF}-2$} & 5007675.56 & 2818816.88 & 1133541.66 \\
\hline & OF- 4 & & & 1476523.13 & 585671.40 \\
\hline & OF-1 & \multirow{2}{*}{ OF-3 } & 14758461.51 & 2818816.88 & 982314.27 \\
\hline & OF-4 & & & 1476523.13 & 828837.19 \\
\hline Total energy (kWh/yr) & & & 19766137.07 & 8590680.00 & 3530364.52 \\
\hline \multirow{4}{*}{$9(\mathrm{OF}-2 \& \mathrm{OF}-3)$} & OF-2 & \multirow{2}{*}{ OF-1 } & & 3758422.50 & 2744664.91 \\
\hline & OF-3 & & 1715349.78 & 9261826.88 & 8026547.50 \\
\hline & OF-2 & \multirow{2}{*}{ OF-4 } & 866162.49 & 3758422.50 & 1368443.07 \\
\hline & OF-3 & & & 9261826.88 & 3468561.26 \\
\hline Total energy (kWh/yr) & & & 2581512.27 & 26040498.75 & 15608216.74 \\
\hline
\end{tabular}




\begin{tabular}{|c|c|c|c|c|c|}
\hline \multicolumn{6}{|c|}{ TABLE A3 (continued) } \\
\hline Alternatives & $\begin{array}{l}\text { Local pumping } \\
\text { - OF }\end{array}$ & $\begin{array}{c}\text { Inter-location } \\
\text { transfer - OF }\end{array}$ & $\begin{array}{c}\text { Inter-location } \\
\text { transfer (kWh/yr) }\end{array}$ & $\begin{array}{l}\text { Local pumping } \\
(\mathrm{kWh} / \mathrm{yr})\end{array}$ & $\begin{array}{l}\text { STP energy operating } \\
\text { (kWh/yr - } 25 \% \text { of total } \\
\text { operating energy) }\end{array}$ \\
\hline \multirow{4}{*}{$10(\mathrm{OF}-2$ \& OF-4) } & OF-2 & \multirow{2}{*}{ OF-1 } & 1838825.62 & 3758422.50 & 3003699.98 \\
\hline & OF-4 & & & 1476523.13 & 615338.24 \\
\hline & OF-2 & \multirow{2}{*}{ OF-3 } & 7220237.15 & 3758422.50 & 1156146.25 \\
\hline & OF-4 & & & 1476523.13 & 646740.83 \\
\hline Total energy $(\mathbf{k W h} / \mathbf{y r})$ & & & 9059062.77 & 10469891.25 & 5421925.30 \\
\hline \multirow{4}{*}{11 (OF-3 \& OF-4) } & OF-3 & \multirow{2}{*}{ OF-1 } & 1715349.78 & 9261826.88 & 4120516.01 \\
\hline & OF-4 & & & 1476523.13 & 6080221.56 \\
\hline & OF-3 & \multirow{2}{*}{ OF-2 } & 2573777.32 & 9261826.88 & 3567375.61 \\
\hline & OF-4 & & & 1476523.13 & 1012575.11 \\
\hline Total energy $(\mathbf{k W h} / \mathbf{y r})$ & & & 4289127.10 & 21476700.00 & 14780688.29 \\
\hline \multirow[b]{3}{*}{12 (OF-1,OF-2 \& OF-3) } & OF-1 & \multirow{3}{*}{ OF-4 } & & 2818816.88 & 1164410.62 \\
\hline & OF-2 & & 866162.49 & 3758422.50 & 1368443.07 \\
\hline & OF-3 & & & 9261826.88 & 3468561.26 \\
\hline Total energy (kWh/yr) & & & & 15839066.25 & 6001414.95 \\
\hline \multirow{3}{*}{13 (OF-1,OF-2 \& OF-4) } & OF-1 & \multirow{3}{*}{ OF-3 } & & 2818816.88 & 10838419.28 \\
\hline & OF-2 & & 7220237.15 & 3758422.50 & 20308395.50 \\
\hline & OF-4 & & & 1476523.13 & 37148229.74 \\
\hline Total energy (kWh/yr) & & & & 8053762.50 & 68295044.52 \\
\hline \multirow{3}{*}{14 (OF-1,OF-3 \& OF-4) } & OF-1 & \multirow{3}{*}{ OF-2 } & & 2818816.88 & 125751669.76 \\
\hline & OF-3 & & 2573777.32 & 9261826.88 & 231194944.01 \\
\hline & OF-4 & & & 1476523.13 & 425241658.29 \\
\hline Total energy (kWh/yr) & & & & 13557166.88 & 782188272.05 \\
\hline \multirow{3}{*}{15 (OF-2, OF-3 \& OF-4) } & OF-2 & \multirow{4}{*}{ OF-1 } & & 3758422.50 & 1438624874.35 \\
\hline & OF-3 & & 1715349.78 & 9261826.88 & 2646054804.69 \\
\hline & OF-4 & & & 1476523.13 & 4866867951.09 \\
\hline Total energy (kWh/yr) & & & & 14496772.50 & 8951547630.13 \\
\hline
\end{tabular}

